\title{
COLLECTIVE BEHAVIORS OF AN INTERCONNECTED BIONIC ASSEMBLY SYSTEM - WORKING SCENARIOS \& STRATEGIES
}

\author{
KATALINIC, B.
}

Abstract: This paper describes the concept of integration of biologically inspired self-organizing complex flexible assembly System in Computer integrated production environment. The functional System integration is realized through vertical and horizontal communication. The two way vertical communication between central control system and assembly units realizes at the shop floor the functions and aims which are defined at higher level. The horizontal communication between all assembly units realizes self-organizing functions at level of sequence of assembly operations of one Single product. This communication structure is a backbone of integration of task orientation and self-organization of the assembly system. In that way functionality and efficiency from one side and high flexibility, re-configurability and robustness of the assembly system from the other side can be reached.

Key words: collective behavior, bionic assembly system, self-organization, communication strategy, autonomous agent
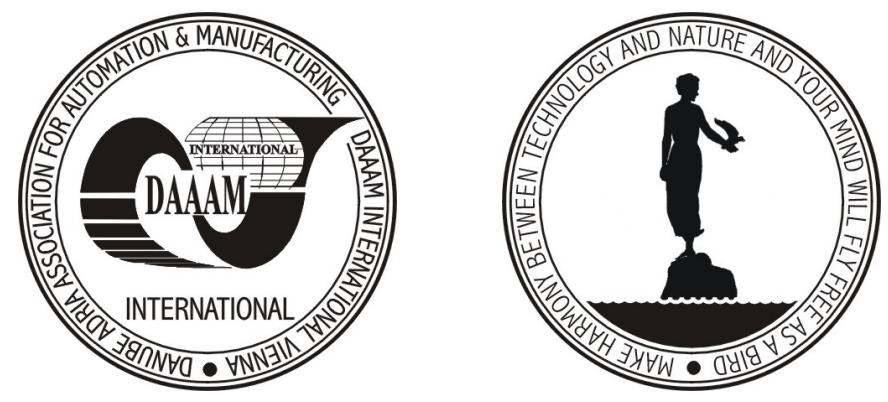

Authors' data: Prof. Dr. DDr. mult. h.c. Katalinic B.[ranko], Vienna University of Technology, Karlsplatz 13, A-1040 Wien, Austria, katalinic@mail.ift.tuwien.ac.at

This Publication has to be referred as: Katalinic, B. (2007). Collective Behaviors of an Interconnected Bionic Assembly System - Working Scenarios \& Strategies, Chapter 58, in DAAAM International Scientific Book 2007, B. Katalinic (Ed.), DAAAM International, ISBN 3-901509-60-7, ISSN 1726-9687, Vienna, Austria DOI: $10.2507 /$ daaam.scibook.2007.58 